\title{
Un Rastro del Romance de Fontefrida, en la Poesía Gauchesca
}

$\mathbb{E}^{\mathrm{L}}$ único caso hasta ahora registrado de la existencia del romance de Fontefrida en Hispanoamérica, parece ser el mencionado por Pedro Henríquez Ureña y Bertram D. Wolfe en Romances tradicionales en Méjico. ${ }^{1}$

Sin embargo, en el Diálogo entre Jacinto Chano, capataz de una estancia en las islas del Tordillo, y el gaucho de la Guatdia del Mon$t e,{ }^{2}$ del escritor uruguayo Bartolomé Hidalgo (1788-1822), hallamos los versos 73 y siguientes, que dicen:

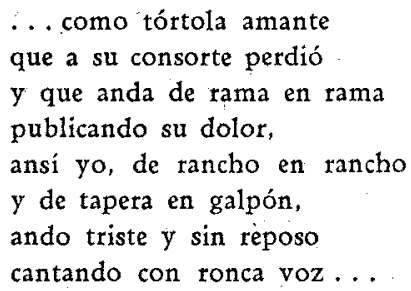

Estos versos, abstracción hecha de algunas palabras de color local, presentan en forma muy parecida el tema de la tórtola viuda del romance de Fontefrida.

Pudiera uno preguntarse si este tema. hallado en el Bestiario y presente en la mayor parte de las literaturas, aparece en Bartolomé Hidalgo procedente del romance español o de un brote local de la tradición común.

El escritor argentino Ricardo Rojas, al estudiar a Hidalgo, dice en una nota, como de paso, que los antes citados versos "coinciden, en forma y fondo, con otros de la lírica anónima". 
Nos inclinamos a estimar que esos versos son resonancia, recuerdo o derivación del romance, pareciendo argumento de suficiente fuerza para sostenerlo el hecho de que Hidalgo usara en ellos el asonante en ó que es el mismo del romance de Fontefrida.

Pudiera oponerse a tal opinión la de que la inexistencia de versiones de Fontefrida en las colecciones de romances recogidos en la América hispana (excepto el caso anotado por Henríquez Ureña) permite dudar de que el de Fontefrida fuera un romance tradicionalmente cantado en el Río de la Plata y que, por lo tanto, no debió ser conocido por Bartolomé Hidalgo.

E1 hecho de no haber sido recogidas versiones de Fontefrida de la tradición popular argentina y uruguaya en estos últimos años en que, a sugerencia de don Ramón Menéndez Pidal, tal labor ha comenzado a realizarse, nada implica en cuanto a la posible existencia de dicho romance como tradicional en esa región hace más de un siglo.

Por otra parte, aun aceptando la inexistencia tradicional de Fontefrida en el Río de la Plata, ello no había de ser obstáculo insuperable para su conocimiento y empleo por Hidalgo. En efecto, en contra de antiguas y románticas ideas acerca de la personalidad de dicho escritor, hoy sabemos - gracias especialmente a los trabajos de Martiniano Leguizamón y de Mario Falcao Espalter ${ }^{4}$ - que lejos de ser, como se había dicho, un barbero semianalfabeto, Hidalgo fué un hombre culto, escritor neoclásico a la moda de su tiempo en no pocas ocasiones, que por razones de propaganda patriótica y política usó en otras las formas gauchescas. Por lo tanto, su conocimiento del romance de Fontefrida (y de otros materiales del romancero), ${ }^{5}$ si no procedía de haberlo oído cantar, bien pudiera ser resultado de sus lecturas y aun estimarse un rasgo culto del autor.

¿Dónde pudo Hidalgo, en sus días y en su tierra, leer el romance de Fontefrida, si no lo conocía por tradición? Nada se opone a la existencia en bibliotecas conventuales y escolares y en manos de las antiguas familias rioplatenses de viejos romanceros que, como nos demuestra Leonard, ${ }^{6}$ con tanta abundancia habían figurado en los registros de envíos de libros de España a sus posesiones ultramarinas.

El empleo del asonante en ó a todo lo largo del Diálogo gauchesco a que venimos refiriéndonos parece que había de traer como de la mano el uso por Hidalgo de unos versos en el mismo asonante 
procedentes del Romance de Fontefrida, ya le fuera éste tradicional o literariamente conocido.

\author{
Luis Monguió, \\ Mills College, \\ California.
}

\title{
NOTAS
}

1 En Homenaje a Menéndez Pidal, II, Madrid, 1925, p. 389: "Don Victoriano Salado Alvarez, en su mencionado attículo 'Sobre la poesía popular americana' (en La Unión Hispanoameticana, de Madrid, de enero de 1920) dice: «Rara será la persona que no haya escuchado la bella canción, probablemente con ritmo antiguo, que comienza: 'Fontefrida, Fontefrida - Fontefrida con amor'... No hemos podido encontrar otros rastros de este romance en Méjico, pero sabemos por el señor don Sälomón de la Selva que en Nicaragua se canta: Fonterrabia, Fonterrabia, - Fonterrabia con amor»."

2 Véase este Diálogo en la edición de Eleuterio F. Tiscornia, Poetas gauchescos, Buenos Aires, 1940.

3 Ricardo Rojas, Obras, viII, La literatura argentina, Los gauchescos, I, Buenos Aires, 1924, p. 472, notas 2 y 3.

4 Mattiniano Leguizamón, El primer poeta criollo del Río de la Plata, Buenos Aires, 1917, y numerosos artículos posteriores. Mario Falcao Espalter, El poeta uruguayo Bartolomé Hidalgo, Madrid, 1929.

5 En el mismo Diálogo de Hidalgo hállase el verso 231 que dice: "quien tal hizo, que tal paguee." Llama la atención porque esta frase reproduce el viejo refrán español (registrado en el Vocabulario de tefranes del maestro Gonzalo Correas, Madrid, 1906, pp. 339-340) o repite el "quien tal hace que tal pague", último verso de un romance de los llamados moriscos, uno de los romanceros artísticos sobre Zaide (véase por ejemplo en Agustín Durán, Romancero general, I, no 56) y es bien conocido que aunque este romance fué sumamente popular en España en el siglo XVII, los romances moriscos no son materia tradicional en América (véase Julio Vicuña Cifuentes, Romances populares y vulgates recogidos de la tradición oral chilena, Santiago de Chile, 1912, pp.

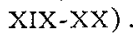

6 Irving A'. Leonard, Romances, of chivalty in the Spanish Indies with some Registros of shipments of books to the Spanish Colonies, Berkeley, California, 1933, p. 15.

$20 *$ 
